Supporting Information

For

\title{
Mechanistic Investigation on the Silver-Catalyzed Oxidative Intramolecular Aminofluorination of Alkynes
}

Tao Xu, ${ }^{\dagger}$ Yichen Wu,${ }^{\dagger}$ Zheliang Yuan, ${ }^{\dagger}$ Hairong Guan ${ }^{\dagger}$ and Guosheng Liu ${ }^{\dagger *}$

${ }^{\dagger}$ State Key Laboratory of Organometallics Chemistry, Shanghai Institute of Organic Chemistry, Chinese Academy of Science, 345

Lingling Road, Shanghai, China, 200032; ${ }^{\ddagger}$ Department of Chemistry, University of Cincinnati, P.O. Box 210172, Cincinnati, Ohio

45221-0172, United States

Email: gliu@mail.sioc.ac.cn

General Procedures and Characterization Data of New Compounds

\section{Content}

1. General Considerations............................................. 2

2. General Procedures for Aminofluorination of Alkynes .................S2

3. Kinetics Procedures and Representative Kinetics Data .................S2

4. ESI-MS Experiments........................................ S5 


\section{General Considerations.}

All commercially available compounds were used as received. ${ }^{1} \mathrm{H},{ }^{13} \mathrm{C}$ and ${ }^{19} \mathrm{~F}$ spectra were recorded on a Varian Mercury-400 MHz or a Varian Mercury-300 MHz spectrometer. $\mathrm{CDCl}_{3}$ was purchased from Aldrich. Chemical shift values $(\delta)$ are given in parts per million relative to internal standard TMS (0 ppm for $\left.{ }^{1} \mathrm{H} \mathrm{NMR}\right), \mathrm{CDCl}_{3}$ (77.0 ppm for ${ }^{13} \mathrm{C} \mathrm{NMR}$ ). Flash column chromatography was performed on silica gel 60 (particle size 200-400 mesh ASTM, purchased from Yantai, China) and eluted with petroleum ether/ethyl acetate. Solvents were dried and purified according to the procedure from book titled 'Purification of Laboratory Chemicals'.

\section{General Procedures for Aminofluorination of Alkynes.}

substrates 1 was synthesized according to the literature ${ }^{1}$.

Procedures: In a $8 \mathrm{~mL}$ glass vial, $\mathrm{Li}_{2} \mathrm{CO}_{3}(15 \mathrm{mg}, 0.2 \mathrm{mmol})$, NFSI $(95 \mathrm{mg}, 0.3 \mathrm{mmol})$ and $\mathrm{AgNO}_{3}(7 \mathrm{mg}, 0.04 \mathrm{mmol})$ were dissolved in dry $N, N$-dimethyl acetamide (DMA, $3.0 \mathrm{~mL}$ ), followed by the addition of substrate $1(48 \mathrm{mg}, 0.2 \mathrm{mmol})$. The vial was sealed and the mixture was stirred at $30{ }^{\circ} \mathrm{C}$, and the reaction was monitored by thin lay chromatography (TLC). When the reaction was complete $(5 \sim 10 \mathrm{~h})$, water was added. The mixture was extracted with $\mathrm{Et}_{2} \mathrm{O}$ several times. The combined organic layers were concentrated under vacuum and the residue was purified by column chromatography on silica gel or neutral alumina column with a gradient eluant of petroleum ether and ethyl acetate.

\section{Kinetics Study and Representative Kinetics Data. 3.1 General Information.}

Our mechanistic studies were focused on the oxidative fluorination of $\mathbf{1}$. At the beginning of the reaction (at $35{ }^{\circ} \mathrm{C}$ ), the fluorinated product 2 was accompanied by intermediate 4 . Extended reaction time led to complete conversion of $\mathbf{4}$ to 2 . When the reaction was performed at $4{ }^{\circ} \mathrm{C}$ (in an ice bath), the only observable speices was 4. In addition, a small amount of (MIC)silver complex was detected in both cases. These observations indicate that intermediate 4 was the initial product from the silver-based catalytic cycle,. Based on the analysis mentioned above, kinetics of the fluoroamination reaction was studied at $4{ }^{\circ} \mathrm{C}$ by in situ React-IR (using the peak at $1149 \mathrm{~cm}^{-1}$ ). Each reaction was monitored to $\sim 10 \%$ conversion, and rate constants were calculated for each reaction using the initial-rate method.

\subsection{Identification of Intermediate 4.}

The structure of $\mathbf{4}$ was identified by ${ }^{1} \mathrm{H}-\mathrm{NMR},{ }^{19} \mathrm{~F}-\mathrm{NMR}$ and HRMS. Due to low stability of $\mathbf{4}$ at room temperature, the spectra of ${ }^{1} \mathrm{H}-\mathrm{NMR}$ and ${ }^{19} \mathrm{~F}-\mathrm{NMR}$ were recorded at $4{ }^{\circ} \mathrm{C}$ with reaction time long enough so that most of the starting material 1 was consumed. The reaction was performed as following: in an oven dried glass vial equipped with a magnetic stir bar, $\mathrm{Li}_{2} \mathrm{CO}_{3}$ (3.7 mg, $0.05 \mathrm{mmol})$, NFSI (26.3 mg, $0.075 \mathrm{mmol})$ and $\mathrm{AgNO}_{3}(8.5 \mathrm{mg}, 0.05 \mathrm{mmol})$ were added to $\mathrm{DMF}-d_{7}(500 \mu \mathrm{L})$ at $4{ }^{\circ} \mathrm{C}$. After several minutes, $1(12.9 \mathrm{mg}, 0.1 \mathrm{mmol})$ was added to the vial. The resulting mixture was then stirred at $4{ }^{\circ} \mathrm{C}$ for $3 \mathrm{~h}$, and subjected to NMR analysis at $4{ }^{\circ} \mathrm{C}$ (Figure S1). The NMR data of 4: ${ }^{1} \mathrm{H}$ NMR (400 MHz, DMF- $\left.d_{7}\right) \delta 10.21\left(\mathrm{~s}, 1 \mathrm{H}, \mathrm{H}^{1}\right), 8.65(\mathrm{~d}$, 
$\left.{ }^{1} J_{H H}=10 \mathrm{~Hz}, 1 \mathrm{H}, \mathrm{H}^{2}\right), 8.52\left(\mathrm{~m}, 1 \mathrm{H}, \mathrm{H}^{3}\right), 8.34\left(\mathrm{~d},{ }^{1} J_{H H}=8.8 \mathrm{~Hz}, 1 \mathrm{H}, \mathrm{H}^{4}\right), 3.64\left(\mathrm{~m}, 2 \mathrm{H}, \mathrm{H}^{5}\right), 2.12$ $\left(\mathrm{s}, 9 \mathrm{H}, \mathrm{CH}_{3}\right), 1.82\left(\mathrm{~m}, 2 \mathrm{H}, \mathrm{H}^{6}\right), 1.63\left(\mathrm{~m}, 2 \mathrm{H}, \mathrm{H}^{7}\right), 1.03\left(\mathrm{t},{ }^{1} J_{H H}=7.6 \mathrm{~Hz}, \mathrm{H}^{8}\right) .{ }^{19} \mathrm{~F}$ NMR $(376 \mathrm{MHz}$, DMF- $\left.d_{7}\right) \delta-106.2(\mathrm{~m}),-121.9(\mathrm{~s})$. This mixture was also analyzed by high resolution ESI-MS: HRMS: $\mathrm{m} / \mathrm{z}(\mathrm{EI})$ calculated $\left[\mathrm{C}_{17} \mathrm{H}_{22} \mathrm{~F}_{2} \mathrm{~N}\right]^{+}: 278.1715$, measured: 278.1704 .<smiles></smiles>

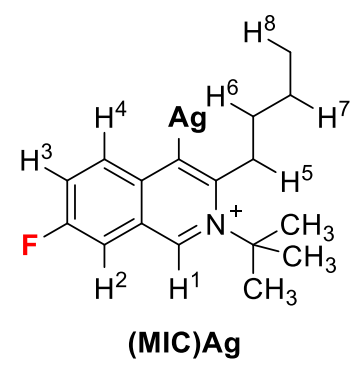

The (MIC)Ag complex was also detected. Characteristic peaks from the ${ }^{1} \mathrm{H}-\mathrm{NMR}$ and ${ }^{19} \mathrm{~F}-\mathrm{NMR}$ spectra are identified. ${ }^{1} \mathrm{H}$ NMR $\left(400 \mathrm{MHz}, \mathrm{DMF}-d_{7}\right) \delta 9.85\left(\mathrm{~s}, 1 \mathrm{H}, \mathrm{H}^{1}\right), 8.74\left(\mathrm{~s}, 1 \mathrm{H}, \mathrm{H}^{2}\right), 8.44(\mathrm{~m}$, $\left.1 \mathrm{H}, \mathrm{H}^{3}\right), 8.20\left(\mathrm{~m}, 1 \mathrm{H}, s p^{2} \mathrm{H}^{4}\right), 3.64\left(\mathrm{~m}, 2 \mathrm{H}, \mathrm{H}^{5}\right), 2.08\left(\mathrm{~s}, 9 \mathrm{H}, \mathrm{CH}_{3}\right), 1.82\left(\mathrm{~m}, 2 \mathrm{H}, \mathrm{H}^{6}\right), 1.63(\mathrm{~m}, 2 \mathrm{H}$, $\left.\mathrm{H}^{7}\right), 1.03\left(\mathrm{t}, J=7.6 \mathrm{~Hz}, 3 \mathrm{H}, \mathrm{H}^{8}\right) .{ }^{19} \mathrm{~F}$ NMR $\left(376 \mathrm{MHz}, \mathrm{DMF}-d_{7}\right) \delta-108.1(\mathrm{~m})$. Unfortunately, this intermediate failed to be isolated in a pure form. The analogous complex with an i-Pr substituent on the nitrogen has been isolated and characterized by X-Ray crystallography. ${ }^{2}$
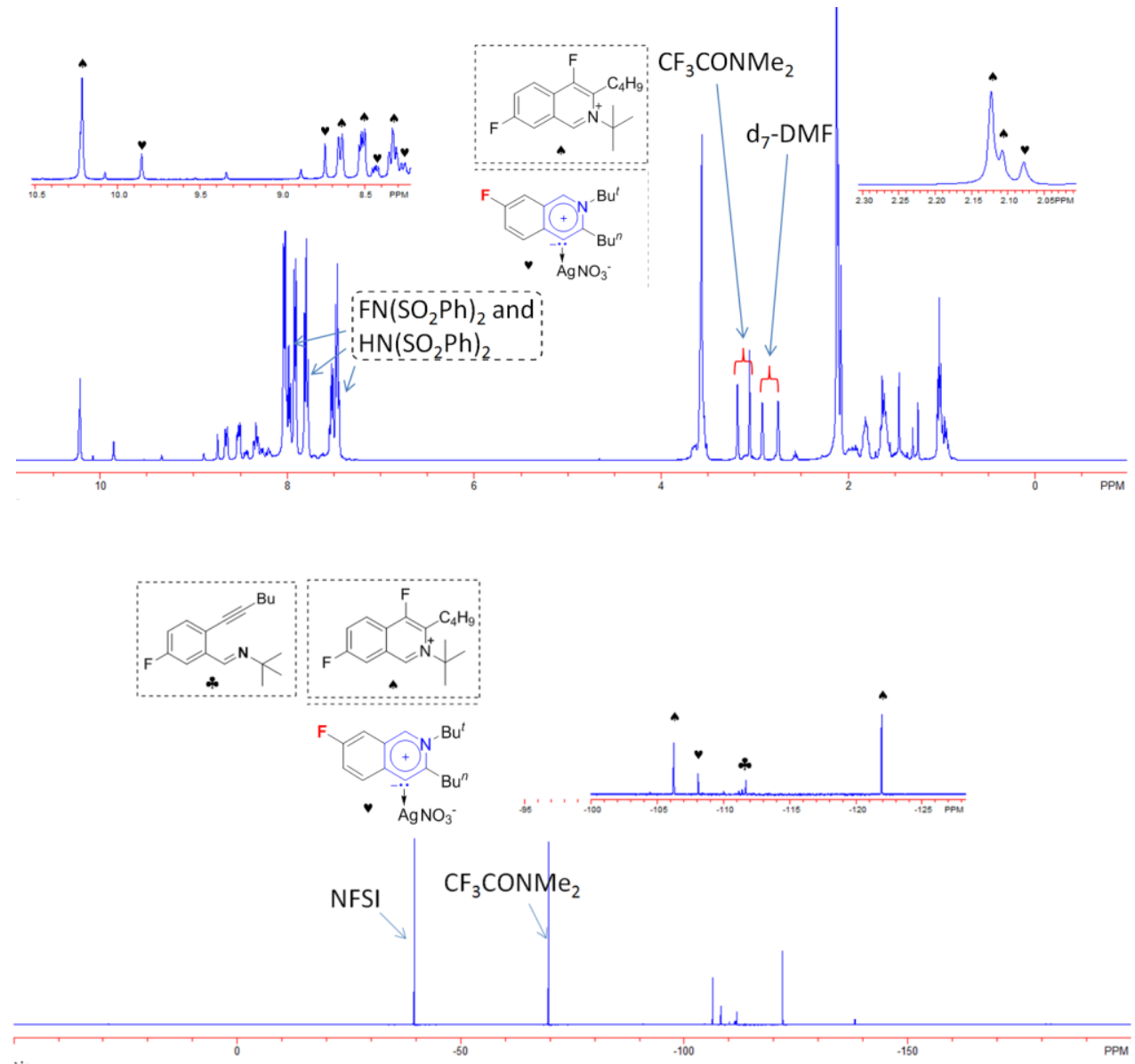

Figure S1. ${ }^{1} \mathrm{H}$ NMR (top) and ${ }^{19} \mathrm{~F}$ NMR (bottom) spectra of the reaction of $\mathbf{1}$ in $d_{7}$-DMF at $4{ }^{\circ} \mathrm{C}$. 
In contrast, at $35{ }^{\circ} \mathrm{C}$, the reaction of $\mathbf{1}$ afforded a mixture of $\mathbf{2}, \mathbf{3}$, and silver intermediate, which can be easily identified by ${ }^{19}$ F NMR spectroscopy (Figure S2).

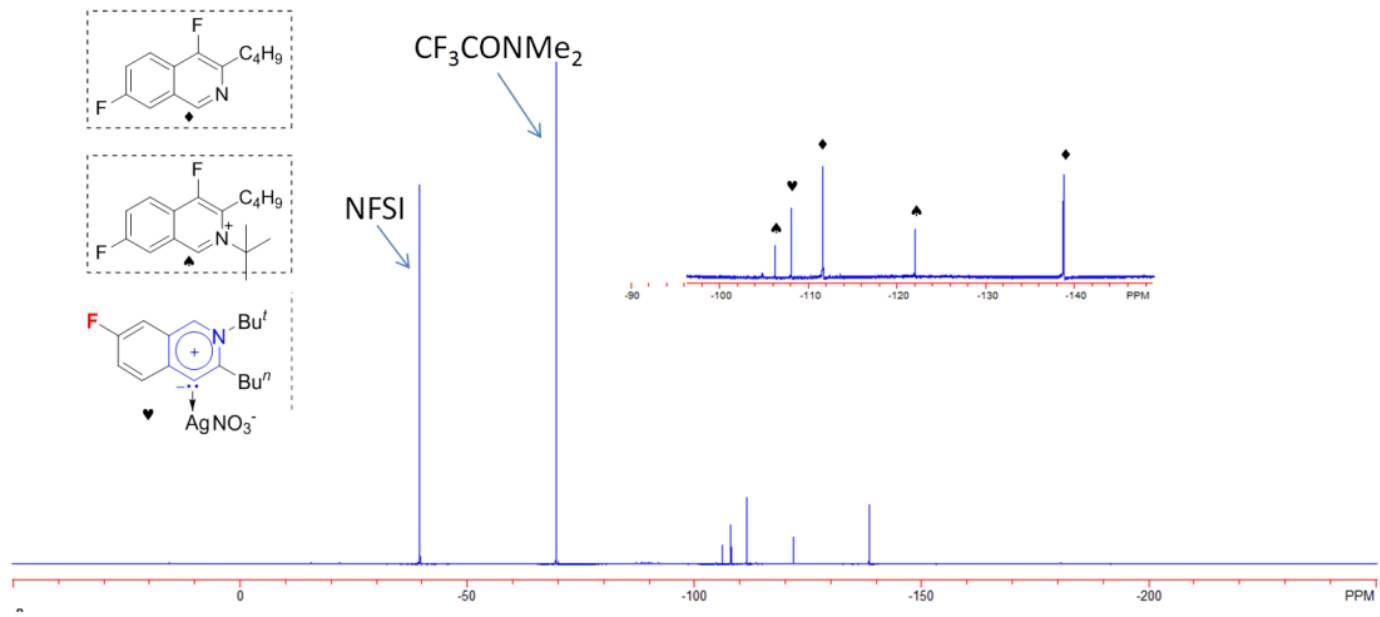

Figure S2. ${ }^{19} \mathrm{~F}$ NMR spectrum of the reaction of $\mathbf{1}$ in $d_{7}$-DMF at $35{ }^{\circ} \mathrm{C}$.

3.3 Reaction Profile of Aminofluorination: In an oven dried custom-made two-necked glass equipped with a magnetic stir bar, $\mathrm{Li}_{2} \mathrm{CO}_{3}(14.8 \mathrm{mg}, 0.2 \mathrm{mmol})$ and DMA $(1400 \mu \mathrm{L})$ were added at $4{ }^{\circ} \mathrm{C}$. IR spectrum of the solution was collected as the background, after which NFSI (105 mg, $300 \mu \mathrm{L}$ of DMA solution, $0.3 \mathrm{mmol}$ ), $\mathrm{AgNO}_{3}(34.0 \mathrm{mg}, 100 \mu \mathrm{L}$ of DMA solution, $0.2 \mathrm{mmol}$ ) and $1(51.8 \mathrm{mg}, 200 \mu \mathrm{L}$ of DMA solution, $0.1 \mathrm{mmol}$ ) were added sequentially. The mixture was then monitored by in situ React-IR (following the band at $1149 \mathrm{~cm}^{-1}$ ) at $4{ }^{\circ} \mathrm{C}$ for $7 \mathrm{~h}$. The representative reaction profile in Figure S3 reveals an increase in product 4. The lack of an induction period allows us to obtain kinetic data via the initial-rate method.

A

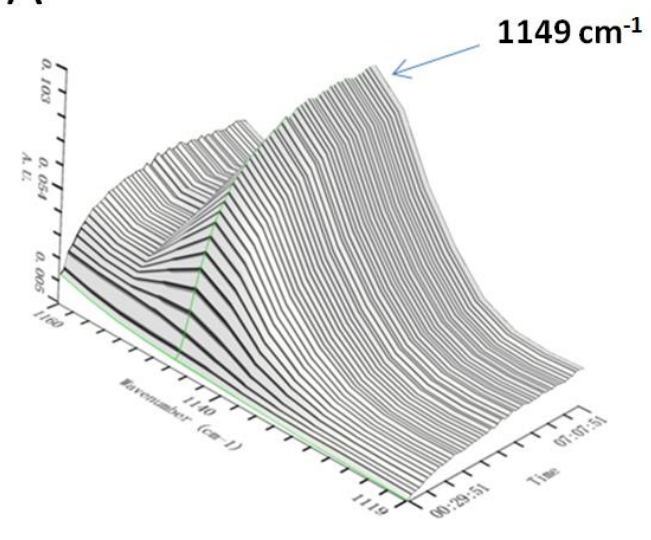

B

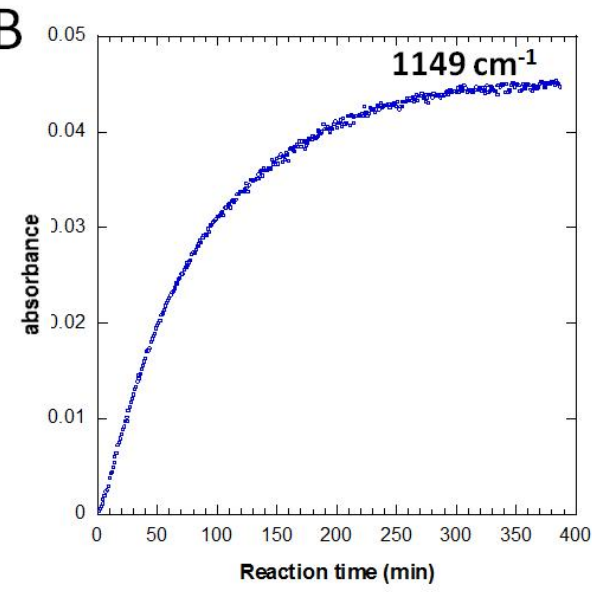

Figure S3. Reaction profile for aminofluorination of $\mathbf{1}$ monitored by in situ React-IR at $4{ }^{\circ} \mathrm{C}$. Reaction conditions: $[1]=0.10 \mathrm{M} ;\left[\mathrm{AgNO}_{3}\right]=0.10 \mathrm{M} ;[\mathrm{NFSI}]=0.15 \mathrm{M} ;\left[\mathrm{Li}_{2} \mathrm{CO}_{3}\right]=0.1 \mathrm{M}$ in DMA at $4{ }^{\circ} \mathrm{C}$. 


\subsection{Representative Kinetics Data.}

Based on the aforementioned procedures, each initial rate was calculated with $10 \%$ conversion. The detailed data were listed in below (Figure S4):
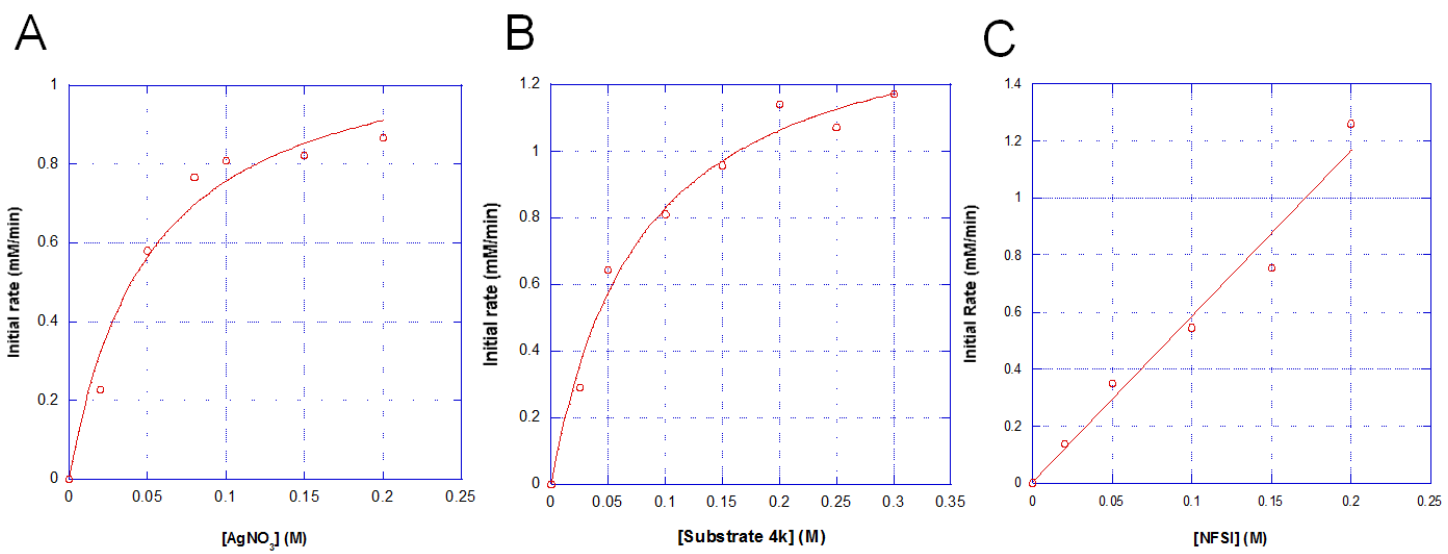

Figure S4. Dependence of the initial rate on catalyst (A), fluorinating reagent (B) and substrate (C). Reaction condition: (A) $[1]=0.10 \mathrm{M} ;[\mathrm{NFSI}]=0.15 \mathrm{M} ;\left[\mathrm{Li}_{2} \mathrm{CO}_{3}\right]=0.1 \mathrm{M} ;\left[\mathrm{AgNO}_{3}\right]=0.02 \sim 0.2 \mathrm{M}$ in DMA at $4{ }^{\circ} \mathrm{C} ;(\mathrm{B})$ $\left[\mathrm{AgNO}_{3}\right]=0.10 \mathrm{M} ;[\mathrm{NFSI}]=0.15 \mathrm{M} ;\left[\mathrm{Li}_{2} \mathrm{CO}_{3}\right]=0.1 \mathrm{M} ;[\mathbf{1}]=0.025 \sim 0.3 \mathrm{M}$ in DMA at $4{ }^{\circ} \mathrm{C} ;(\mathrm{C})[\mathbf{1}]=0.10 \mathrm{M}$; $\left[\mathrm{AgNO}_{3}\right]=0.10 \mathrm{M} ;\left[\mathrm{Li}_{2} \mathrm{CO}_{3}\right]=0.1 \mathrm{M} ;[\mathrm{NFSI}]=0.02 \sim 0.2 \mathrm{M}$ in DMA at $4{ }^{\circ} \mathrm{C}$.

\section{ESI-MS Experiment}

\subsection{ESI-MS(/MS) conditions:}

The ESI-MS and subsequent MS/MS experiments were performed on a Finnigan TSQ Quantum Access ${ }^{\mathrm{TM}}$ triple-quadrupole mass spectrometer (Thermo Scientific, San Jose, CA, USA) equipped with a standard ESI ion source. Nitrogen was used as the sheath gas and auxiliary gas, and argon as the collision gas. The basic ESI conditions were: vacuum, $2.8 \times 10^{-6}$ Torr; spray voltage, $3000 \mathrm{~V}$; capillary temperature, $270^{\circ} \mathrm{C}$; sheath gas pressure, 20 arbitrary units; auxiliary gas pressure, 5 arbitrary units; while the selected collision energy depended on the dissociation capability of the precursor ion. Data acquisition and analysis were carried out with the Xcalibur software package (version 2.0, Thermo Scientific).

Notes: The ions containing Ag gave their representative isotopic clusters in ESI MS spectra, thus the $\mathrm{m} / \mathrm{z}$ values of these $\mathrm{Ag}$ complex ions shown in this paper are the peaks associated with ${ }^{107} \mathrm{Ag}$.

\subsection{ESI-MS Study of $\mathrm{Ag}(\mathrm{I})$-catalyzed amination of compound 1.}

A mixture of 1 (0.5 mmol), $\mathrm{AgNO}_{3}(0.1 \mathrm{mmol}), \mathrm{FN}\left(\mathrm{SO}_{2} \mathrm{Ph}\right)_{2}(0.75 \mathrm{mmol})$, and $\mathrm{Li}_{2} \mathrm{CO}_{3}(0.10$ $\mathrm{mmol}$ ) was dissolved in $1.0 \mathrm{~mL}$ DMF in a $5 \mathrm{~mL}$ reaction vessel cooled at $4^{\circ} \mathrm{C}$ with an ice bath. Due to the high concentrations of reactants, the mixture $(0.01 \mathrm{~mL})$ was diluted to $1 \mathrm{~mL}$ with pure $\mathrm{CH}_{3} \mathrm{CN}$ before ESI-MS analysis. The injection speed of the diluted reaction solution was set to 5 
$\mu \mathrm{L} / \mathrm{min}$. The ESI-MS spectrum for this diluted reaction solution is shown in Figure S5.

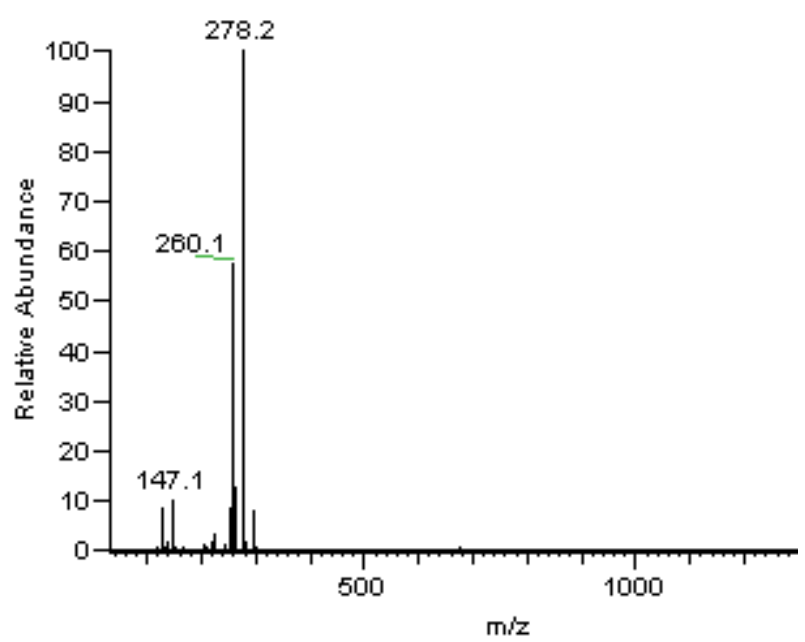

Figure S5. ESI-MS spectrum for the diluted reaction solution, showing the signal of the reactive intermediate $\mathbf{B}$ at $m / z, 278$ and side-reaction intermediate at $m / z, 260$.

The MS/MS spectrum of the intermediate $\mathbf{B}$ at $m / z 278$ and side-reaction intermediate at $m / z 260$ are shown in Figure S5. The proposed degradation pathways for these two intermediates are shown in Scheme S1. In the MS/MS process, the intermediate $\mathbf{B}$ at $m / z, 278$ gave fragmentation ion at $\mathrm{m} / \mathrm{z} 222$ by the loss of neutral 2-methylpropene, which is a final product-forming process. Side-reaction intermediate at $\mathrm{m} / z, 260$ gave fragmentation ion at $m / z 204$ by the loss of neutral 2-methylpropene, which is related to the side product forming process. Depiste low concentration, $\operatorname{Ag}(\mathrm{I})$ complexes were observed with the expected isotopic patterns. 
(a)

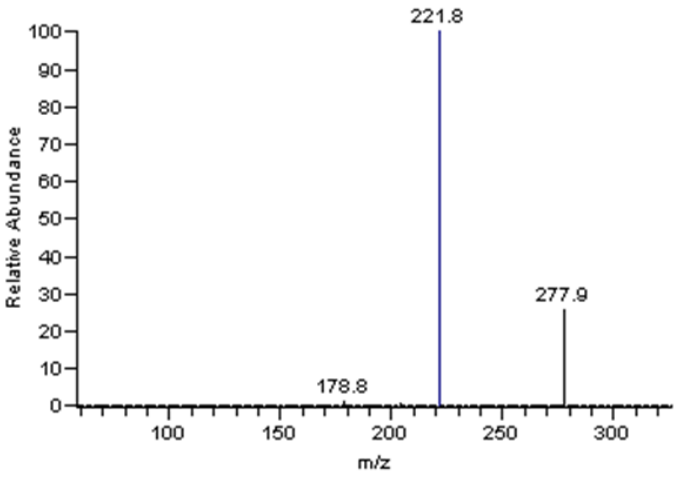

(b)

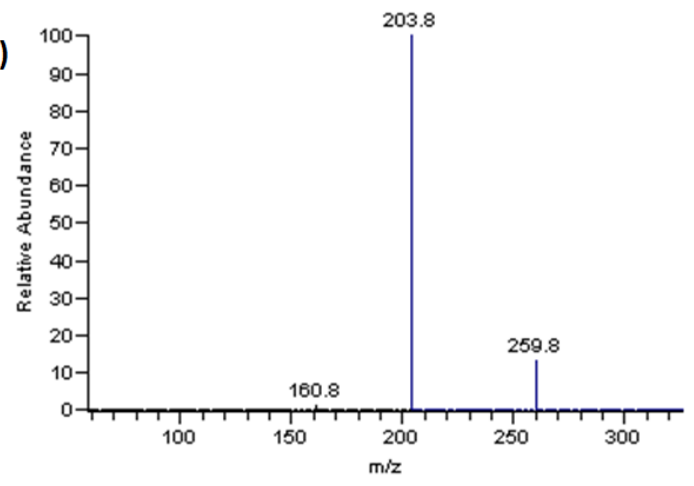

Figure S6. ESI-MS/MS spectra of: (a) the reactive intermediate B at $\mathrm{m} / \mathrm{z} 278$, (b) side reaction intermediate at $m / z 260$.<smiles>CC(C)(C)c1c(F)c2ccc(F)cc2c[n+]1C(C)(C)C</smiles>

$m / z 278$

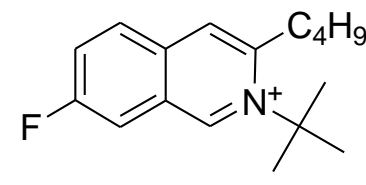

$m / z 260$

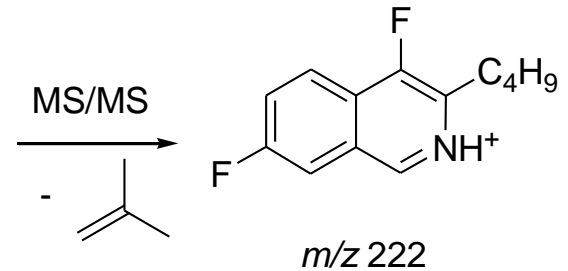

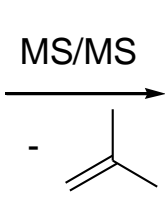

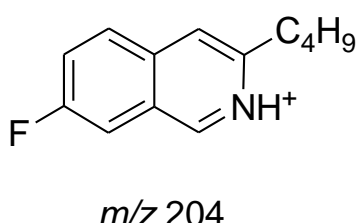

Scheme S1. Proposed degradation pathways for intermediate $\mathbf{B}$ at $\mathrm{m} / \mathrm{z} 278$ and side-reaction intermediate at $\mathrm{m} / \mathrm{z} 260$.

1. Xu, T.; Liu, G. Org. Lett. 2012, 14, 5416.

2. For details, see: Liu, Q.; Yuan, Z.; Wang, H.-Y.; Li, Y.; Wu, Y.; Xu, T.; Leng, X.; Chen, P.; Guo, Y.-L.; Lin, Z.; Liu, G. ACS Catal. 2015, 5, 6732. 